\title{
Design of Luminescent Sulfur-Containing Polynuclear Gold(I) Complexes for Advanced Nanomaterials and Chemosensors
}

\author{
Vivian Wing-Wah Yam* and Eddie Chung-Chin Cheng \\ Department of Chemistry, The University of Hong Kong, Pokfulam Road, \\ Hong Kong, P R China E-Mail:wwyam@hku.hk
}

Received 10 January 2001

A series of high-nuclearity gold(I) sulfido complexes with bridging diphosphine ligands have been synthesized and isolated, with the general formulae of $\left[A u_{10}\left(\mu-P^{\wedge} \mathbf{P}\right)_{4}\left(\mu_{3}-S\right)_{4}\right] X_{2}$ and $\left[A u_{12}\left(\mu-P^{\wedge} \mathbf{P}\right)_{6}\left(\mu_{3}-S\right)_{4}\right] X_{4}$ $\left(P^{\wedge} \mathbf{P}=\right.$ diphosphine; $\mathrm{X}=\mathbf{P F}_{6}$ or $\left.\mathbf{C l O}_{4}\right)$. Intense green and orange emissions were observed upon excitation at $\lambda>350 \mathrm{~nm}$ both in the solid state and in solutions. The green emission has been attributed to originate from excited states derived from the metal-perturbed intraligand (IL) transition while the orange emission

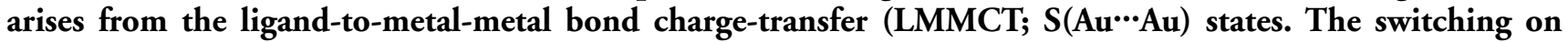
and off of the LMMCT emission in a series of dinuclear gold(I) thiolate complexes with crown ether pendants induced by ion-binding has been demonstrated, and this provides a new strategy for the design of luminescence signalling and chemosensing devices in optoelectronics and sensor technology.

The chemistry of polynuclear gold(I) complexes has aroused much attention over the last couple of decades, owing to the presence of significant gold $\cdots$ gold interactions with energy in the order of 5-10 kcal mol${ }^{-1}$ that is comparable to that of hydrogen bonding (1). This phenomenon, called aurophilicity by Schmidbaur, is attributed to the strong relativistic effects possessed by gold which lower the energy difference between the $5 d$ and the $\sigma s / p$ orbitals and give rise to a more effective configuration mixing of the molecular orbitals $(2,3)$. With a closed-shell electronic configuration of $d^{10}$, gold(I) can, as a result, form stronger homonuclear sub-bonding interactions intermolecularly and/or intramolecularly and give birth to a wide diversity of polynuclear aggregates (1, $3-5)$. In view of the wide applications for $d^{10}$ metal chalcogenides as photovoltaics and photocatalysts (6), an understanding of their intrinsic photophysical properties is essential. However, such studies are often not straightforward since these materials are usually insoluble solids, and their properties are highly dependent on their history and methods of preparation. One approach to assisting with this problem is to synthesize polynuclear metal chalcogenide complexes with well-defined structures of uniform and known sizes, which can act as model systems for such classes of compounds. Using diphosphine ligands with small bite angles, it is possible to avoid insoluble polymer formation and to promote the formation of high-nuclearity soluble gold(I) chalcogenido complexes with novel structures.

\section{COMPLEX SYNTHESIS}

A series of luminescent dodecanuclear and decanuclear complexes with the formulae of $\left[\mathrm{Au}_{12}(\mu \text {-dppm })_{6}\left(\mu_{3}-\right.\right.$ $\left.S)_{4}\right]\left(\mathrm{PF}_{6}\right)_{4}$ and $\left[\mathrm{Au}_{10}\left\{\mu-\mathrm{Ph}_{2} \mathrm{PN}(\mathrm{R}) \mathrm{PPh}_{2}\right\}_{4}\left(\mu_{3}-\mathrm{S}\right)_{4}\right] \mathrm{X}_{2}$ (where dppm $=\mathrm{Ph}_{2} \mathrm{PCH}_{2} \mathrm{PPh}_{2} ; \mathrm{R}=$ alkyl or aryl; $\mathrm{X}=$ $\mathrm{PF}_{6}$ or $\mathrm{ClO}_{4}$ ), respectively, have recently been prepared in acceptable yields from one-pot syntheses using $\mathrm{H}_{2} \mathrm{~S}$ gas as the sulfide source (Scheme 1) (7, 8). Hydrogen sulfide gas was slowly bubbled into a suspension of the dinuclear gold(I) diphosphine chloride complex, $\left[\mathrm{Au}_{2}\left(\mathrm{P}^{\wedge} \mathrm{P}\right) \mathrm{Cl}_{2}\right]\left(\right.$ where $\mathrm{P} \wedge \mathrm{P}=\mathrm{dppm}$ or $\left.\mathrm{Ph}_{2} \mathrm{PN}(\mathrm{R}) \mathrm{PPh}_{2}\right)$, in ethanol/pyridine $(3: 1 \mathrm{v} / \mathrm{v})$. The white suspension readily turned to a clear yellow solution. Removal of the solvents and subsequent metathesis reaction with $\mathrm{NH}_{4} \mathrm{PF}_{6}$ or $\mathrm{LiClO}_{4}$ in methanol afforded a yellow solid. Slow recrystallization of the solid in acetone/diethyl ether gave 


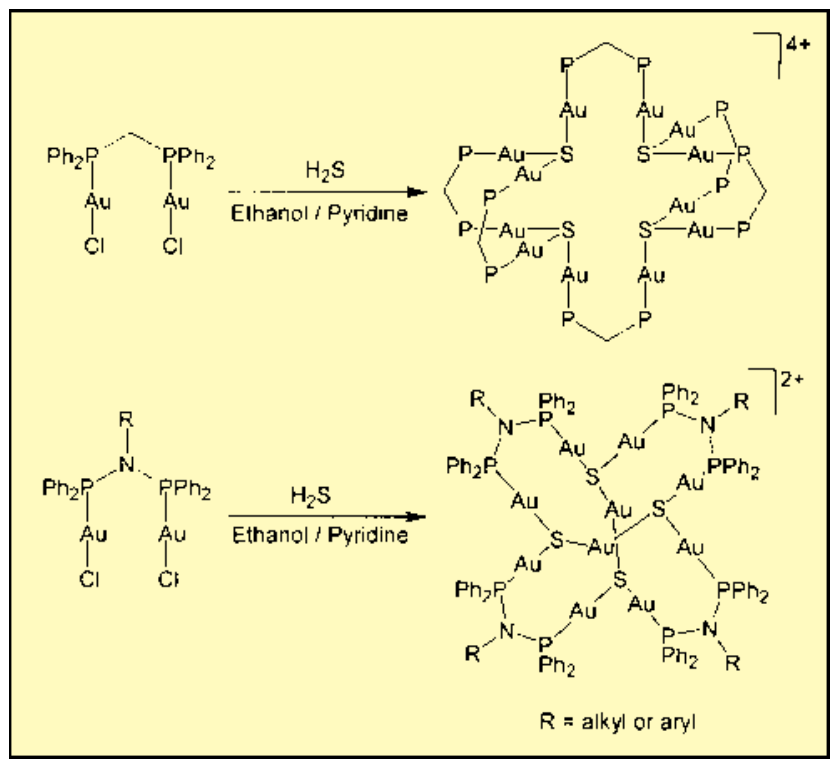

Scheme 1 Synthesis of polynuclear gold(I) sulfido complexes

the dodecanuclear complex as colourless crystals in $85 \%$ yield and the decanuclear complexes as greenish yellow crystals (40-72\% yield). The complexes are stable in air and have good solubilities in acetone, acetonitrile, chloroform and dichloromethane. They have also been shown to remain intact in solution as indicated by solution NMR spectroscopy and positive ESI mass spectrometry. The X-ray crystal structures of $\left[\mathrm{Au}_{12}(\mu-\mathrm{dppm})_{6}\left(\mu_{3}\right.\right.$ $\left.S)_{4}\right]\left(\mathrm{PF}_{6}\right)_{4}$ and $\left[\mathrm{Au}_{10}\left\{\mu-\mathrm{Ph}_{2} \mathrm{PN}\left({ }^{n} \mathrm{Pr}\right) \mathrm{PPh}_{2}\right\}_{4}\left(\mu_{3}-\mathrm{S}\right)_{4}\right]\left(\mathrm{PF}_{6}\right)_{2}$ have been determined and the results published previously $(7,8) \cdot\left[\mathrm{Au}_{12}(\mu-\mathrm{dppm})_{6}\left(\mu_{3}-\mathrm{S}\right)_{4}\right]\left(\mathrm{PF}_{6}\right)_{4}$ shows an interesting 'crossroad-sign' structure with the four $\mathrm{Au}_{3} \mathrm{~S}$ units located at the core and interconnected by six dppm ligands, whereas $\left[\mathrm{Au}_{10}\left\{\mu-\mathrm{Ph}_{2} \mathrm{PN}\left({ }^{n} \mathrm{Pr}\right) \mathrm{PPh}_{2}\right\}_{4}\left(\mu_{3}-\mathrm{S}\right)_{4}\right]\left(\mathrm{PF}_{6}\right)_{2}$ is propellershaped with four $\left[\mathrm{Au}_{2}\left\{\mathrm{Ph}_{2} \mathrm{PN}\left({ }^{n} \mathrm{Pr}\right) \mathrm{PPh}_{2}\right\}\right]$ flaps connected by four sulfur atoms that are further bonded to two interstitial gold atoms. Significant and short intramolecular gold...gold contacts are present in these complexes with distances mostly in the range of 3.00-3.34 $\AA$.

\section{LUMINESCENSE}

The dodecanuclear and decanuclear gold(I) sulfido complexes display rich luminescence properties. The electronic absorption spectrum of $\left[\mathrm{Au}_{12}(\mu-\mathrm{dppm})_{6}\left(\mu_{3^{-}}\right.\right.$ S) $\left.{ }_{4}\right]\left(\mathrm{PF}_{6}\right)_{4}$ in acetonitrile solution at room temperature features an intense absorption at $266 \mathrm{~nm}$ and an absorption shoulder at $332 \mathrm{~nm}$. The high-energy band is assigned as the phosphine-centred intraligand transition, whereas the low-energy one is suggestive of transitions characteristic of the polynuclear gold(I) $\mu_{3}$-sulfido system as there is no similar band in the spectrum of $\left[\mathrm{Au}_{2}(\mathrm{dppm}) \mathrm{Cl}_{2}\right]$. Intense long-lived orange and green emissions are produced upon excitation of $\left[\mathrm{Au}_{12}(\mu-\right.$ $\left.\mathrm{dppm})_{6}\left(\mu_{3}-\mathrm{S}\right)_{4}\right]\left(\mathrm{PF}_{6}\right)_{4}$ in the solid state and in solution, respectively, at room temperature with excitation wavelength longer than $350 \mathrm{~nm}$. The radiative lifetime in the microsecond range is supportive of an excited state of triplet parentage. With reference to our previous spectroscopic work on the related $d^{10}$ chalcogenido systems $(9,10)$, we tentatively assign the emission as originating from triplet states of a ligand-to-metal-metal bond charge transfer (LMMCT; $S \rightarrow A u \cdots A u$ ) character that mixed with metal-centred $(d s / d p)$ states modified by gold …gold interaction. From the electronic absorption spectral data of the decanuclear complexes, one can easily see that there is an additional low energy absorption band at ca 400-418 nm. Likewise, the absence of this lowenergy band in the electronic absorption spectrum of the precursor complexes $\left[\mathrm{Au}_{2}\left\{\mathrm{Ph}_{2} \mathrm{PN}(\mathrm{R}) \mathrm{PPh}_{2}\right\} \mathrm{Cl}_{2}\right]$ readily suggests that the band is likely to originate from a ligandto-metal charge transfer transition modified by gold $\cdots$ gold interaction, or a LMMCT $(\mathrm{S} \rightarrow \mathrm{Au} \cdots \mathrm{Au})$ transition. The absorption bands of higher energy at $c a 266-268 \mathrm{~nm}$ and 326-336 nm, which are also exhibited by the $\mathrm{Ph}_{2} \mathrm{PN}(\mathrm{R}) \mathrm{PPh}_{2}$ ligands and $\left[\mathrm{Au}_{2}\left\{\mathrm{Ph}_{2} \mathrm{PN}(\mathrm{R}) \mathrm{PPh}_{2}\right\} \mathrm{Cl}_{2}\right]$, are attributed to an intraligand transition and a metalperturbed intraligand transition, respectively. Excitation in the solid state and in solution with visible light at room temperature and at $77 \mathrm{~K}$ results in intense dual phosphorescence in the green and orange-red regions. Figure 1 shows the emission spectrum of $\left[\mathrm{Au}_{10}\left\{\mathrm{Ph}_{2} \mathrm{PN}\left({ }^{n} \mathrm{Pr}\right) \mathrm{PPh}_{2}\right\}_{4} \mathrm{~S}_{4}\right]\left(\mathrm{PF}_{6}\right)_{2}$ in degassed dichloromethane at $298 \mathrm{~K}$. The low-energy emission in the orange-red region is tentatively assigned to originate from triplet states of a LMMCT $(\mathrm{S} \rightarrow \mathrm{Au} \cdots \mathrm{Au})$ character that mixed with metal-centred $(d s / d p)$ states, while the high-energy emission in the green is attributed to the metal-perturbed phosphine-centred phosphorescence.

In addition, we have recently reported the synthesis and luminescence properties of a series of dinuclear gold(I) thiolato complexes with bridging diphosphine ligands $(11,12)$. They have a general formula $\left[\mathrm{Au}_{2}(\mu-\mathrm{P} \wedge \mathrm{P})(\mathrm{SR})_{2}\right] \quad[\mathrm{P} \wedge \mathrm{P}=$ bis(dicyclohexylphosphino)naphthalene (dcpn), $\mathrm{Ph}_{2} \mathrm{PN}\left(\mathrm{R}^{\prime}\right) \mathrm{PPh}_{2} \quad\left(\mathrm{R}^{\prime}=\mathrm{C}_{6} \mathrm{H}_{11}, \mathrm{C}_{6} \mathrm{H}_{5}, \quad{ }^{n} \mathrm{Pr}, \quad{ }^{i} \mathrm{Pr}\right)$; $\left.\mathrm{R}=\mathrm{C}_{6} \mathrm{H}_{4} \mathrm{~F}-p, \mathrm{C}_{6} \mathrm{H}_{4} \mathrm{Cl}-p, \mathrm{C}_{6} \mathrm{H}_{4} \mathrm{CH}_{3}-p\right]$. A gold $\cdots$ gold separation of $3.4379 \AA$ has been observed in the solid-state crystal structure of $\left[\mathrm{Au}_{2}\{\mu\right.$ $\left.\left.\mathrm{Ph}_{2} \mathrm{PN}\left(\mathrm{C}_{6} \mathrm{H}_{11}\right) \mathrm{PPh}_{2}\right\}\left(\mathrm{SC}_{6} \mathrm{H}_{4} \mathrm{~F}-p\right)_{2}\right]$, indicative of the absence of gold $\cdots$ gold interactions although the bis(diphenylphosphino)amine ligand has a bite distance within the separation well suited for short gold *..gold 


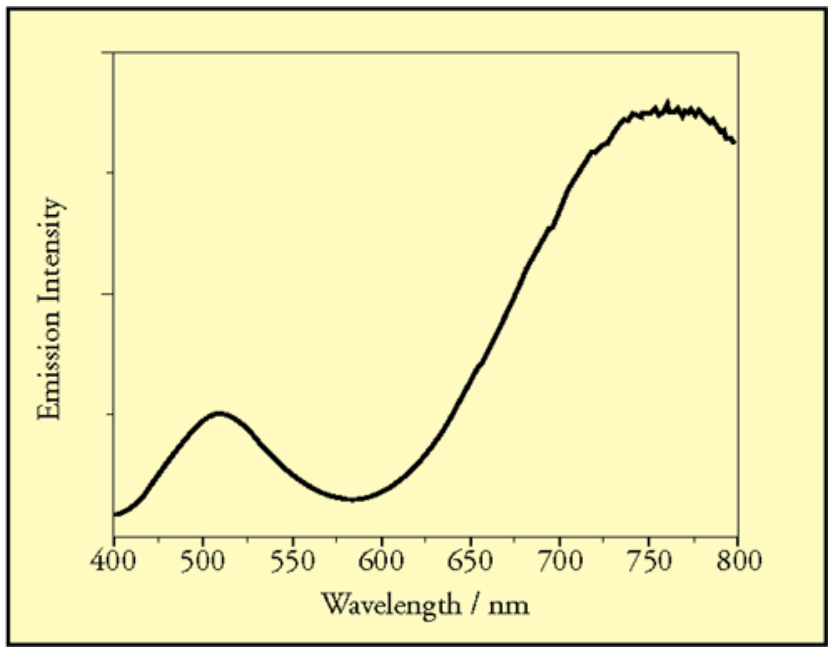

Figure 1 Emission spectrum of $\left[A u_{10}\left\{\mu-P h_{2} P N\left({ }^{n} P r\right) P P h_{2}\right\}_{4}\right.$ $\left(\mu_{3}-S\right)_{4} J\left(P F_{6}\right)_{2}$ in degassed dichloromethane at $298 \mathrm{~K}$.

contacts to exist $(\mathrm{P}(1) \ldots \mathrm{P}(2) 2.87 \AA)$. The absence of short $\mathrm{Au} \cdots \mathrm{Au}$ and $\mathrm{S} \cdots \mathrm{S}$ contacts $(\mathrm{S}(1) \cdots \mathrm{S}(2) 5.75 \AA)$ as well as the highly unsymmetrical structure could be a consequence of the steric requirements of the ligand. Detailed photophysical studies indicate that the lowenergy orange emission derived from the triplet excited states of a LMMCT $(\mathrm{S} \rightarrow \mathrm{Au} \cdots \mathrm{Au})$ origin can only be observed in the solid state at $77 \mathrm{~K}$. The gold...gold distances are supposed to be closer as a result of the higher rigidity and less floppy nature of the structure at low temperature. Conversely, the complexes $\left[\mathrm{Au}_{2}(\mathrm{dcpn})(\mathrm{SR})_{2}\right]$ give the low-energy LMMCT emission in the solid state even at room temperature, most probably due to the rigid nature and the small bite distance of the dcpn ligand which holds the two gold centres close to each other. Similar findings have also been observed by Fackler and Bruce with other related gold(I) thiolate complexes, in which both the nature of the thiolates and the metalmetal separation were found to have significant effects on the luminescence properties of the complexes $(13-16)$. In addition, a series of polynuclear gold(I) complexes with phosphine ligands have also been shown to exhibit luminescence behaviour dependent on the strength of the gold $\cdots$ gold interaction (17).

\section{CHEMOSENSORS}

In view of the recently identified and significant need to search for host molecules that can selectively recognize specific guest molecules at a specific receptor site and produce measurable physical changes, we have paid special attention to the molecular design of chemosensors that would involve optical signal transduction, particularly in luminescence signalling. The discovery of the unique spectroscopic and luminescence features of polynuclear gold(I) sulfido and dinuclear gold(I) thiolate complexes that are associated with weak gold $\cdots$ gold interactions has prompted us to adopt the switching on and off of the weak gold $\cdots$ gold interactions as a new strategy for the molecular design of luminescence chemosensors and signalling devices. A series of dinuclear gold(I) complexes with bridging diphosphines and crownether functionalized thiolate ligands, together with their crown-free analogues as controls, $\left[\mathrm{Au}_{2}(\mu\right.$ $\left.\left.\mathrm{P}^{\wedge} \mathrm{P}\right)(\mathrm{SR})_{2}\right]\left[\mathrm{P}^{\wedge} \mathrm{P}=\mathrm{dppm}, \mathrm{dcpm}, \mathrm{Ph}_{2} \mathrm{PN}\left(\mathrm{R}^{\prime}\right) \mathrm{PPh}_{2}\left(\mathrm{R}^{\prime}\right.\right.$ $\left.=\mathrm{C}_{6} \mathrm{H}_{11}, \mathrm{C}_{6} \mathrm{H}_{5},{ }^{n} \mathrm{Pr}\right) ; \mathrm{R}=4$-(benzo-15-crown-5), $\left.\mathrm{C}_{6} \mathrm{H}_{3}\left(\mathrm{OCH}_{3}\right)_{2}-3,4\right]$, have been designed and synthesized (18). Prominent absorption and emission spectral changes with well-defined isosbestic and isoemissive points, respectively, were observed upon addition of potassium ions to the complexes with 4mercaptobenzo-15-crown-5 moieties. Figure 2 shows the emission spectral changes of $\left[\mathrm{Au}_{2}(\mathrm{dppm})(4-\mathrm{S}\right.$ benzo-15-crown-5 $)_{2}$ ] when potassium ions are added in dichloromethane/methanol solution. Similar spectral changes were not observed with the crown-free analogues in the control experiments. The formation of a new orange-red emission band due to the LMMCT $(\mathrm{S} \rightarrow \mathrm{Au} \cdots \mathrm{Au})$ triplet upon addition of potassium ions was attributed to the 'switching-on' of the gold $\cdots$ gold interactions induced by ion-binding (Scheme 2). Log $K_{s}$ values ( $K_{s}=$ binding constant) of 3.4 and 4.0 towards potassium ions were obtained for the complexes $\left[\mathrm{Au}_{2}(\mathrm{dppm})(4-S \text {-benzo-15-crown-5) })_{2}\right]$ and $\quad\left[\mathrm{Au}_{2}(\mathrm{dcpm})(4-S \text {-benzo-15-crown-5) })_{2}\right]$,

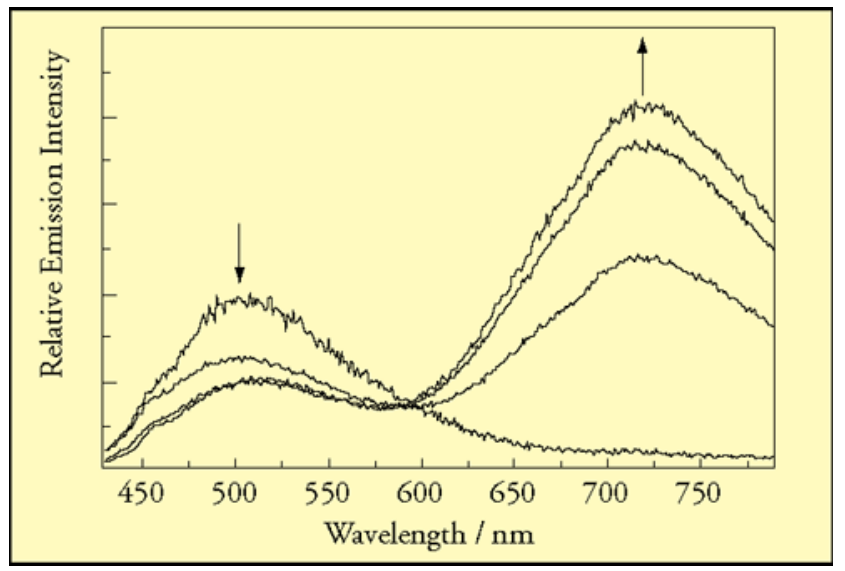

Figure 2 Emission spectral changes of $\left[\mathrm{Au}_{2}(\mathrm{dppm})(4-S\right.$-benzo15-crown-5 $\left.)_{2}\right]\left(1.7 \times 10^{-3} \mathrm{~mol} \mathrm{dm}^{-3}\right)$ upon addition of various concentrations of potassium ions in $\mathrm{CH}_{2} \mathrm{Cl}_{2} / \mathrm{MeOH}\left(1: 1 \mathrm{v} / \mathrm{v} ; 0.1 \mathrm{M}^{n} \mathrm{Bu}_{4} \mathrm{NPF}_{6}\right)$ 


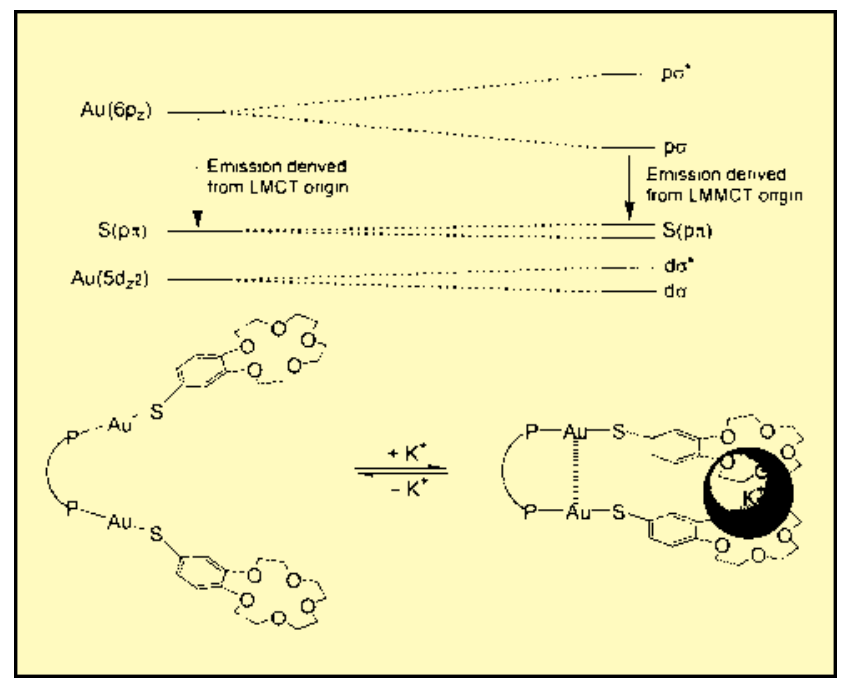

Scheme 2 Schematic representation of the orbital splittings expected with $A u \cdot$. Au interactions in dinuclear gold(I) thiolate complexes with bridging diphosphine ligands

respectively. The spectral changes could readily be reversed upon the addition of an excess of free crown ethers, indicative of a reversible binding process. Emission studies confirmed the results and a $\log K_{s}$ value of 3.2 was obtained for $\left[\mathrm{Au}_{2}(\mathrm{dppm})(4-\mathrm{S}\right.$-benzo15-crown-5 $\left.)_{2}\right]$. Such a switching on-and-off process in emission has also been shown to be much less pronounced in complexes with a dcpn bridging ligand. It is likely that the higher rigidity and the configuration of the dcpn ligand would render the two gold centres close to each other in the complexes even in the absence of potassium ions.

The utilization of such switching on and off of weak gold $\cdots$ gold interactions in the design of ioninduced luminescence chemosensors and signalling devices should represent a new research strategy and direction for the future development of chemosensors and molecular optoelectronic switching devices.

\section{ACKNOWLEDGEMENT}

The work described in this paper has been fully supported by a grant from the Research Grants Council of the Hong Kong Special Administrative Region, China (HKU 7100/98P). Support from The University of Hong Kong is also gratefully acknowledged. VW-WY and EC-CC acknowledge the Croucher Foundation for the award of the Croucher Senior Research Fellowship and the Croucher Scholarship, respectively. We also wish to express our appreciation to Dr Kung-Kai Cheung and Professor Zhong-Yuan Zhou for solving the crystal structures of the polynuclear gold complexes described.

\section{ABOUT THE AUTHORS}

Professor Dr Vivian-W-W Yam is the Chair of Chemistry and is currently the Head of the Department of Chemistry at The University of Hong Kong. She has produced over 120 publications since 1987. Her research interests include the photophysics and photochemistry of transition metal complexes with electronic configurations of $d^{6}, d^{8}$ and $d^{10}$, and their related applications in advanced materials and sensor technology. Eddie C-C Cheng studied for his $\mathrm{PhD}$ with Professor Yam on the synthesis and luminescence behaviour of polynuclear coinage metal chalcogenide and chalcogenolate complexes.

\section{REFERENCES}

1 H. Schmidbaur, Chem. Soc. Rev., 1995, 391

2 H. Schmidbaur, Gold Bull., 1990, 23, 11; 2000, 33, 3

3 P. Pyykkö, Chem. Rev., 1988, 88, 563

4 'Gold: Progress in Chemistry, Biochemistry and Technology', ed. H. Schmidbaur, Wiley, 1999

5 P. Pyykkö, Chem. Rev., 1997, 97, 597

6 'Sulfur: Its Significance for Chemistry, for the Geo-, Bio- and Cosmosphere and Technology', eds. A. Müller, B. Krebs, Elsevier, 1984

7 V. W.-W. Yam, E. C.-C. Cheng and K.-K. Cheung, Angew. Chem. Int. Ed., 1999, 38, 197

8 V. W.-W. Yam, E. C.-C. Cheng, Z.-Y. Zhou, Angew. Chem. Int. Ed., 2000, 39, 1683

9 V. W.-W. Yam and K. K.-W. Lo, Comments Inorg. Chem., 1997, 19, 209, and references therein

10 V. W.-W. Yam and K. K.-W. Lo, Chem. Soc. Rev., 1999, 323

11 V. W.-W. Yam, C.-L. Chan and K.-K. Cheung, J. Chem. Soc., Dalton Trans., 1996, 4019

12 V. W.-W. Yam, C.-L. Chan, C.-K. Li and K. M.-C. Wong, Coord. Chem. Rev., in press

13 J. M. Forward, D. Bohmann, J. P. Fackler, Jr. and R. J. Staples, Inorg. Chem., 1995, 34, 6330

14 Z. Assefa, B. G. McBurnett, R. J. Staples, J. P. Fackler, Jr., B. Assmann, K. Angermaier and H. Schmidbaur, Inorg. Chem., 1995, 34, 75

15 R. Narayanaswamy, M. A. Young, E. Parkhurst, M. Ouellette, M. E. Kerr, D.M. Ho, R. C. Elder, A. E. Bruce and M. R. M. Bruce, Inorg. Chem., 1993, 32, 2506

16 W. B. Jones, J. Yuan, R. Narayanaswamy, M. A. Young, R. C. Elder, A. E. Bruce and M. R. M. Bruce, Inorg. Chem., 1995, 34, 1996

17 J. M. Forward, J. P. Fackler, Jr., Z. Assefa in 'Optoelectronic Properties of Inorganic Compounds', eds. D. M. Roundhill, J. P. Fackler, Jr., Plenum, New York, 1999, p.195

18 V. W.-W. Yam, C.-K. Li and C.-L. Chan, Angew. Chem. Int. Ed., 1998, 37, 2857 